\title{
Wave Run-up of a Possible Anak-Krakatau Tsunami on Planned and Optimized Jakarta Sea Dike
}

\author{
M.R. Badriana ${ }^{1, a)}$, H. Bachtiar ${ }^{2, b)}$, D. Adytia ${ }^{1, c)}$, L. Sembiring ${ }^{2, d)}$, \\ Andonowati $^{1, \mathrm{e})}$, and E. van Groesen ${ }^{1, \mathrm{f})}$ \\ ${ }^{1}$ LabMath-Indonesia, Jl. Dago Giri 99, Bandung \\ ${ }^{2}$ Balai Litbang Pantai, PUSLITBANG-SDA, Kementerian PUPR, Jl. Musi-Buleleng, Bali \\ a)riambadriana@gmail.com; b)huda.bachtiar@gmail.com; \\ c)didit@labmath-indonesia.org; ${ }^{\mathrm{d}}$ leo.sembiring@gmail.com; \\ e) Corresponding author: andonowati@labmath-indonesia.org; f) groesen@labmath-indonesia.org
}

\begin{abstract}
The infrastructural plans in the Jakarta Bay to reduce risks of flooding in Jakarta city comprise a large Sea Dike that encloses a retention lake. Part of the planned dike has the shape of the iconic Garuda bird. This paper shows that if in the future an explosion of Anak Krakatau will occur with strength $1 / 4^{\text {th }}$ of the original Karkatau 1883 explosion, wave crests of $11 \mathrm{~m}$ and troughs of $6 \mathrm{~m}$ may collide against the bird's head. As an alternative example, a more optimized design of the dike is constructed that reduces the maximal wave effects considerably.
\end{abstract}

\section{INTRODUCTION}

Indonesia's capital city Jakarta suffers from regular floodings, caused by soil inclination, increased run-off from the Bogor region and rising sea level. The 'National Capital Integrated Coastal Development' (NCICD) programme [1] is being designed to prevent Jakarta from future flooding. In the so-called "phase B" of that programme, an outer sea dike is being considered to be built in the Jakarta Bay $(J B)$. This dike will create a retention area, with a water level that is controllable by large pumping devices so that the maximal expected run-off water from the Jakarta main land can be accommodated.

The present design of this 'giant sea wall' contains a part that will be the northern boundary of a reclamation lake in the form of the 'Garuda', the bird that is the national symbol of Indonesia. Looking in the northerly direction towards the Java Sea, the wings of the bird form a convex shaped curved dike, with in the middle the bird's head that may accommodate a planned business centre [1].

The water levels in the $J B$ are under normal circumstances well known and rather modest, with significant wave height less than $2 \mathrm{~m}$, and the semi-diurnal tidal range of $1 \mathrm{~m}$;

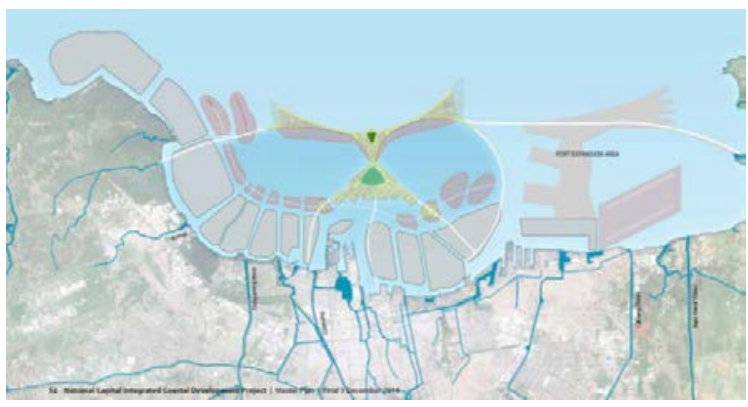
occasional storm surges from (local winds induced by) cyclones in the South China Sea are less than $1 \mathrm{~m}$. Hence, modern design techniques and constructions will be sufficient to construct dikes that can withstand these water heights, also when including expected sea level rise (less than $1 \mathrm{~m}$ until the end of the century) and somewhat larger wave heights from climate change. [1]

For large infrastructural works that should last for centuries, in a seismic active country as Indonesia, it is necessary to take effects of future earthquakes and possible resulting tsunamis into account. There are two reasonable sources that could lead to significant tsunami waves in the $J B$. One is a tsunami generated by tectonic motion, a tsunamigenic earthquake along the subduction zone in the Indian Ocean which could propagate waves into the Sunda Strait that diffract into the Java Sea and from there into the $J B$, see [1] for a preliminary study. 
Another source for a tsunami is a large earthquake and explosion in the Krakatau area. The previous explosion of the Krakatau in 1883 caused huge tsunami waves in the Sunda Strait, and diffracted waves into the Java Sea. In the $J B$ wave heights of some $5 \mathrm{~m}$ occurred, as we know from documented elevation measurements at that time at two different places [2] and tsunami simulations for this case as presented in [3]. The continuously growing remainder of Krakatau, Anak Krakatau (AK), could possibly lead to a similar, but probably smaller explosion (and resulting tsunami) in the coming centuries.

This paper investigates the run-up heights of such possible tsunami waves on the Jakarta wall. Since the time of occurrence and (somewhat related to that) the strength of any future tsunami cannot be predicted scientifically, we choose to look at the effect of an explosion of Anak Krakatau with a strength roughly one quarter of the original Krakatau explosion. Then wave heights (crest-trough) of $2 \mathrm{~m}$ will be found in the $J B$. This choice leads to wave heights in a linear regime, which makes it possible to scale results of run-up heights with the scaling in energy content. The details of the tsunami generation and the entrance into the $J B$ will be explained, after having provided some details about the HAWASSI software that has been used for all the wave simulations in various nested subdomains.

Having available the tsunami waves that propagate through the Java Sea and diffract and refract into the $J B$, the effect of the waves on the sea wall can be investigated. Elementary knowledge of wave collision against hard walls suggest already that the convex part of the Garuda wall will lead to wave guidance along the wall of the incoming waves from the North-Western direction, which may lead to much higher elevations than when colliding against a straight or concave wall. Accurate simulations have confirmed these expectations: crest and trough heights of around $5 \mathrm{~m}$ will appear at the wings of the Garuda. Moreover, collision of the guided waves along the western wing against the bird's head will lead to almost two time higher values there; details will be described.

Because of the undesired high colliding waves against the Garuda wall, alternative designs have been investigated. Keeping the form of the Garuda, but allowing a rotation of the bird, lower run-up is found if the Garuda is rotated such that the direction of the incoming waves is perpendicular to the bird, but lowest waves are found when Garuda is positioned parallel to the incoming waves, as will be shown.

Removing the constraint that the Garuda shape should be part of the sea wall, we will describe optimized wall shapes given certain constraints. Optimal forms are arcs of a circle with a radius that can be chosen such that the enclosed wet area has a prescribed value and such that the length of the arc-wall is as short as possible. Simulations show that then wave heights are mostly less than twice the incoming wave heights.

Conclusions and remarks will finish the paper.

\section{HAWASSI VARIATIONAL BOUSSINESQ MODEL VBM}

All simulations presented in this paper have been obtained with HAWASSI-VBM, software under license by LabMath-Indonesia; see the website [4] for more details and references to publications with many test cases of simulations compared to measurements. VBM is a Variational Boussinesq Model that evolves phase resolved waves over any bathymetry and in complex geometries. The equations are of Boussinesq type, i.e. the interior flow is modelled, and the dynamics is governed by the continuity equation and the momentum equation using the elevation and potential at the surface that depend on horizontal variables only. The equations are framed in Hamiltonian form, which guarantees energy conservation. A finite element implementation with piece-wise linear splines on an unstructured grid that takes into account the local bottom depth guarantees efficient simulations. The interior flow is modelled with a small number of Airy functions to make sure that dispersive effects are correctly calculated. VBM has facilities to calculate fully nonlinear.

All simulation results in this paper have been obtained with the linear version of the code with one Airy profile.

\section{EFFECTS IN JAKARTA BAY OF AN ANAK KRAKATAU TSUNAMI}

There are various simulations of the tsunami generated by the explosion of the Krakatau in 1883. Different from [5], in [3] the phreatomagmatic explosion model was used for the tsunami-initiation. Width and height in the generation area can be tuned to determine tsunami properties of energy (wave height) and period. Using the 1883 measurement data of wave heights in the $J B$, the initiation parameters could be chosen to get a good match with the simulations. In a similar way we adjusted the initiation parameters as a model for a possible future Anak Krakatau explosion.

As stated in the introduction, we choose parameters to get approximately half the wave height of that of the Krakatau explosion. In Fig. 1 we show comparison of wave heights in the $J B$ : waves of $4 \mathrm{~m}$ and period 2 hrs of the original Krakatau explosion and waves of $2 \mathrm{~m}$ and period 15 min of the modelled Anak Krakatau. 
For the simulation from the Krakatau area, over the Java Sea and into the $J B$, a depth-dependent grid was used with maximal grid size of $500 \mathrm{~m}$ in the deepest areas.

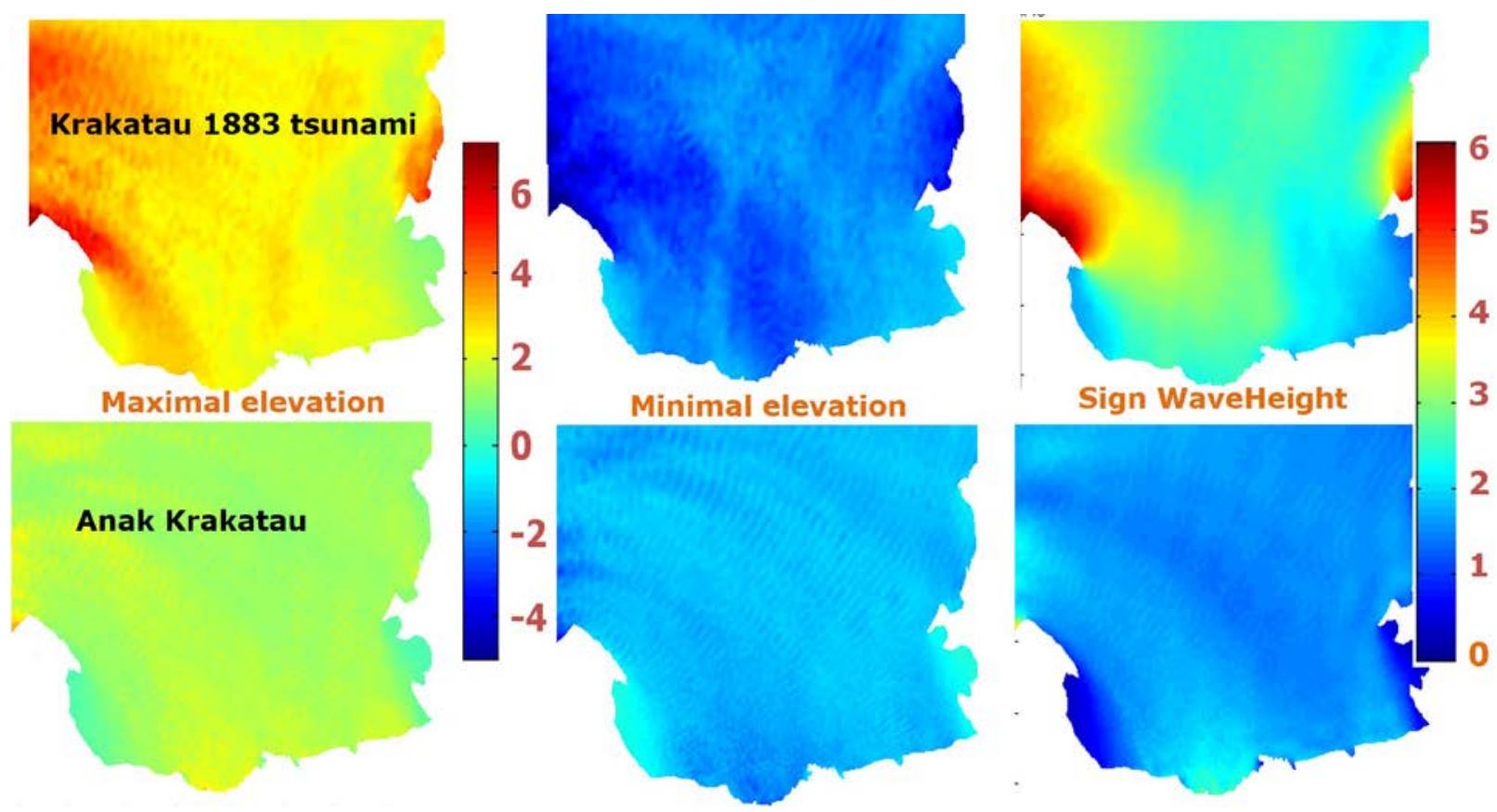

FIGURE 1. Tsunami elevation and wave heights in the $J B$ : from left to right the maximal and minimal elevation and the wave height for simulations of the original Krakatau explosion (upper) and for the modelled explosion of Anak Krakatau (lower).

\section{TSUNAMI WAVES ON PRESENT GARUDA DESIGN}

The waves arriving form the Krakatau area towards the north coast of the $J B$ are used to influx waves for simulations in a subdomain that consists of the Jakarta bay; grid sizes can then be as small as $200 \mathrm{~m}$ in shallower areas. Simulations were performed without and with the presence of the Garuda wall. Fig.2 shows results of maximal and minimal elevations in these two cases, together with the significant wave height.

Although not of main direct interest, it can be observed that for both cases very high waves occur at the boundaries and in the canals of the reclamation areas in the North-Western part of the bay, from $+11 \mathrm{~m}$ to $-5 \mathrm{~m}$. Similar high waves are found at the Garuda; simulations clearly show the wave guiding along the wings which may run in different directions at different times, depending on details of the incoming waves. Collision against the bird's head lead to the highest waves, from $+11 \mathrm{~m}$ to $-5 \mathrm{~m}$, as shown also from simulations on a smaller subdomain around the Garuda wall, see Fig.2.

\section{TSUNAMI WAVES ON ROTATED GARUDA}

Keeping the Garuda form as part of the dike, but changing the design by allowing a rotation of the bird in nearly the same area, will reduce the extreme wave heights when wave guiding can be prevented as much as possible. Two cases will be shown here. The first one is a positioning so that the waves collide in an almost frontal (orthogonal) way; focusing is then still present, but wave guiding is somewhat less, albeit still in both directions, see the upper plots of Fig.3. A much better design is to place the Garuda as much as possible parallel to the main incoming waves; then waves will approach the wall mainly because of diffraction, and little wave guiding is expected. The lower plots in Fig. 3 show indeed much lower waves with most crests and troughs less than $1 \mathrm{~m}$. 


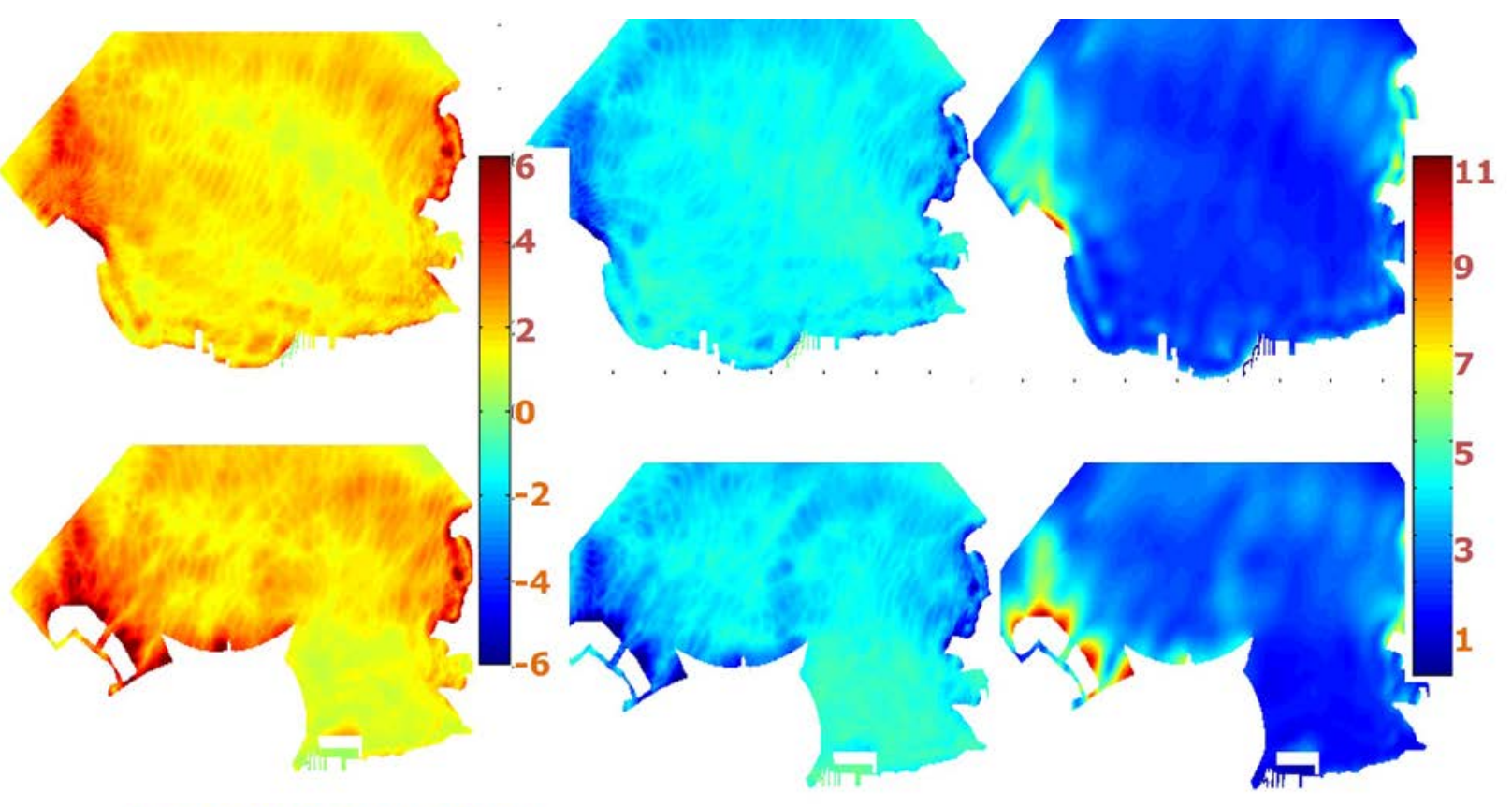

Maximal elevation
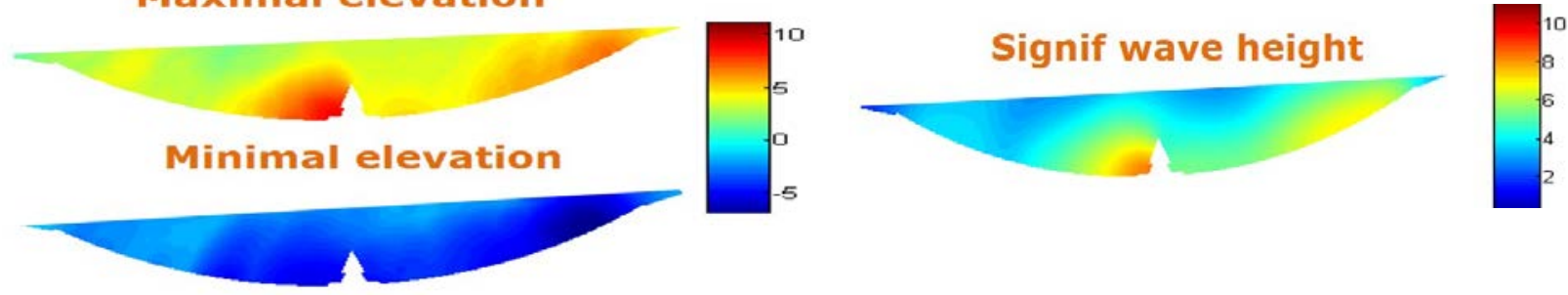

FIGURE 2. The upper rows show tsunami elevations and wave heights in the Jakarta bay and in the bay with the Garuda wall: the maximal and minimal elevation and the significant wave height. Simulation results in a small simulation domain close to the wall (bottom) show the maximal and minimal elevations (left) and the significant wave height (right).

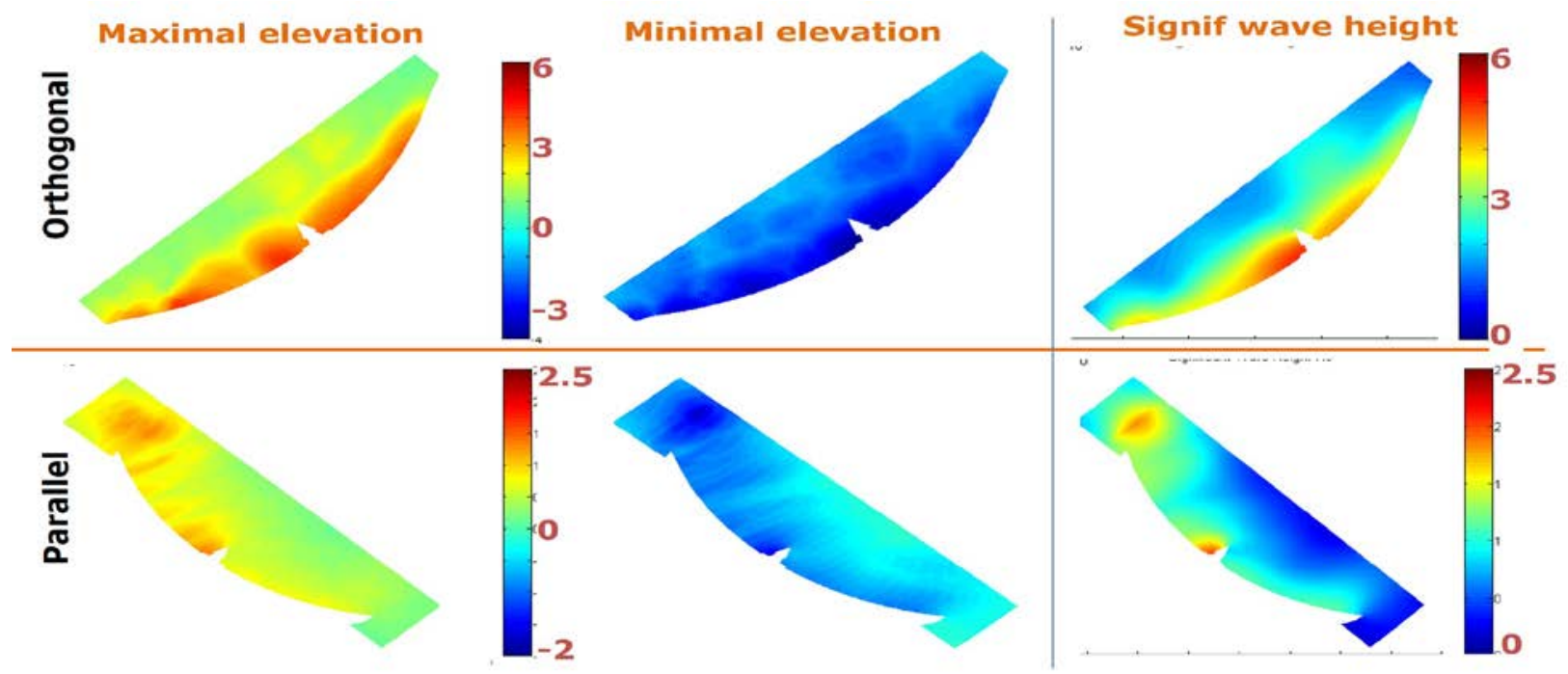

FIGURE 3. Plots of wave heights at two rotated Garuda walls: rotation such that incoming tsunami waves are mostly orthogonal to the wall (top) and parallel with the wall (bottom). Shown are the maximal (left), the minimal elevation (middle) and the significant wave height (right). 


\section{OPTIMAL WALL DESIGN}

Since a convex wall will focus the incoming waves, wave heights will be encountered that are (much) larger than twice the incoming wave height, as seen above. A concave wall, on the other hand, will defocus the waves, leading to less than two times the incoming wave height away from the wall. This is illustrated in Fig.4 where maximal amplitudes are indicated that will arise at positions of coherent interference of multiple waves.
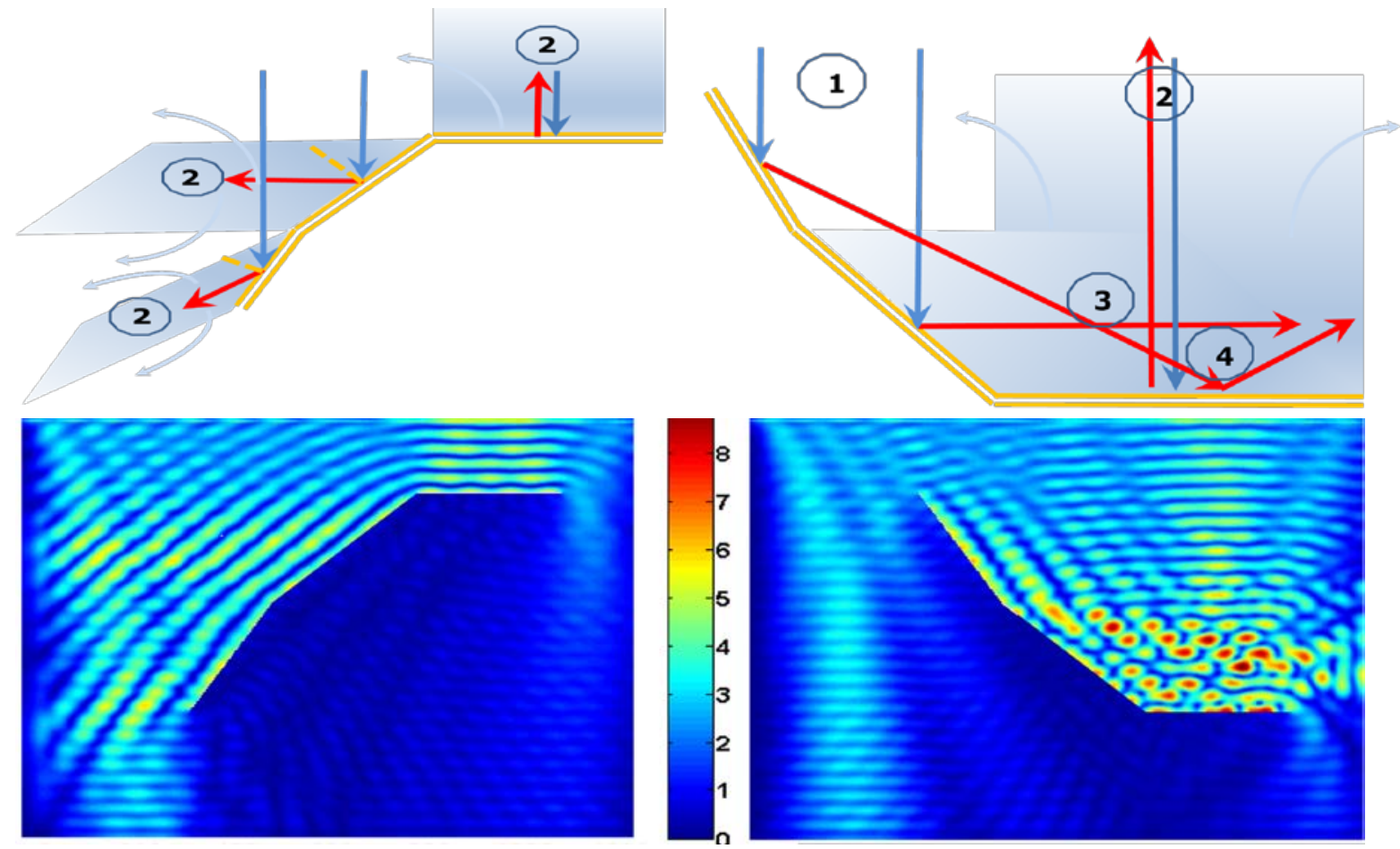

FIGURE 4. In the upper row are shown incoming harmonic waves (blue) and some of the (possibly multiple) reflected waves (red) colliding at a concave wall (at the left) and a convex wall (right). Ray counting provides the maximal amplitude at points where waves are in phase. In the lower row density plots are shown of the wave heights (crest-trough) from a numerical simulation of incoming harmonic waves from the north with unit amplitude, period 7s above depth of 25m (wavelength is 75m) on the concave (at left) and the convex wall, showing the large difference in wave height.

Since the tsunami waves enter the $J B$ from the NW-direction, we design a wall that will be concave for these waves, and actually for waves from any outward direction. An additional constraint for the design is that the wall should enclose a retention lake that has a minimal area, estimated in [1] to be between 75 and $160 \mathrm{~km}^{2}$ depending on hydrological conditions before periods of heavy rain. Moreover, the harbour Tanjung Priok should remain outside the wall. A wall satisfying these constraints will be called optimal if moreover the length of the wall is as small as possible to reduce costs.

The design starts with drawing the straight line from the most North-Western reclamation island to the west side of Tanjung Priok. A retention lake with prescribed area requires additional space east of the constructed line. Hence the task is to design a concave wall of minimal length enclosing the remaining area.

The famous isoperimetric problem states that the circle is the shape that encloses the maximal area for given length of the boundary. Already Queen Dido knew 3 millennia ago a consequence of this fact, namely that the closed domain formed by an arc of a circle and the chord encloses the maximal area for minimal total length of the boundary. Hence, the given length of the chord and the required total enclosed area produces the radius of the circle, piece of which forms the arc that is of our interest as the concave wall. In Fig. 5 the relation between the length of the arc and the area enclosed is given for the case that the chord length is $20 \mathrm{~km}$, and an example of an optimal design is given at the right in Fig.5. Simulations of the collision of tsunami waves against this wall are given in Fig.6, and show that the maximal wave heights are less than twice the incoming waves along most of the wall; higher waves near the endpoints can be avoided by local changes in the design. 

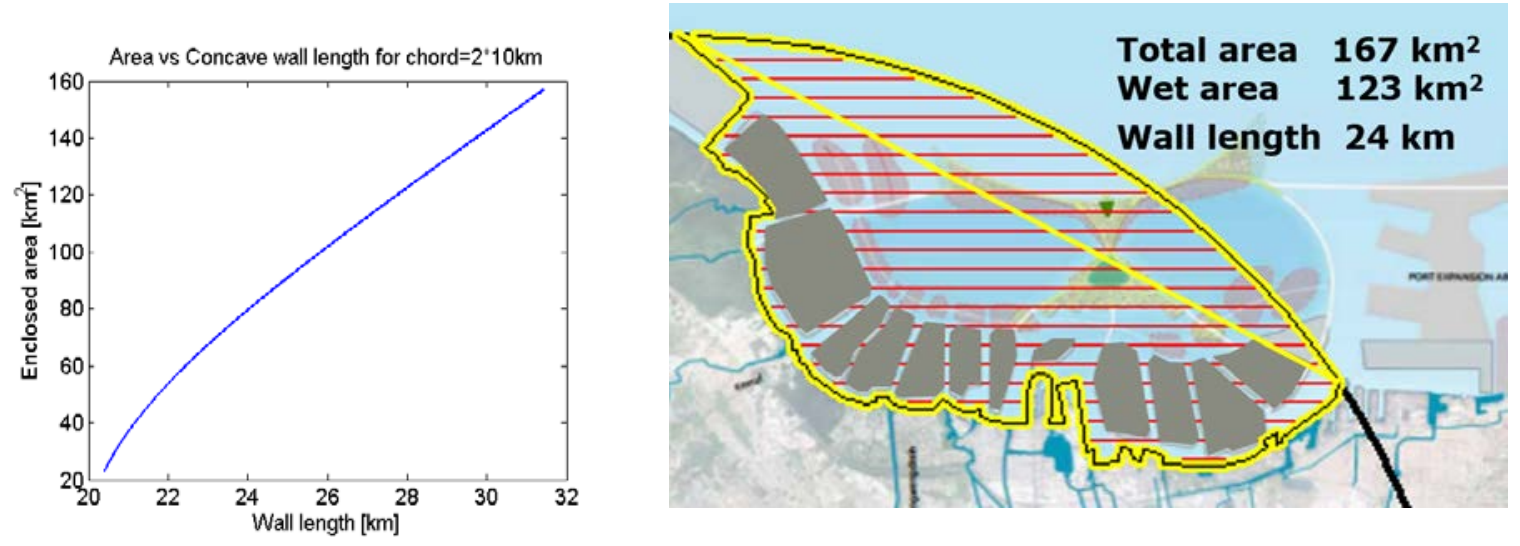

FIGURE 5. At the left the relation between arc length (horizontal) and enclosed area (vertical) for the case that the length of the chord is $20 \mathrm{~km}$. At the right an example of a concave wall with total enclosed wet area $123 \mathrm{~km}^{2}$.

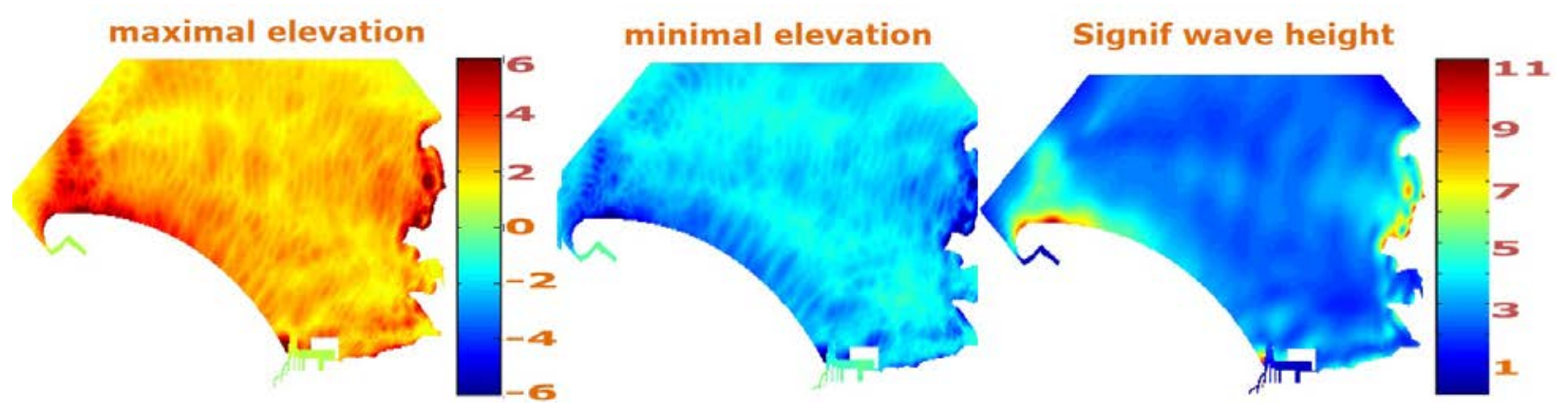

FIGURE 6. Density plots of wave heights in $J B$ with the optimized concave wall shown in Fig.5 at right.

\section{CONCLUSIONS AND REMARKS}

The software HAWASSI-VBM that was used for all simulations has proven to be very capable, stable and reliable in performing the simulations for various study cases. The dispersive properties are essential to obtain realistic waves in the Jakarta bay and at the wall. The possibility to use depth-adjusting grids make results more accurate in reasonable computation times. Although only the linear version of the model has been used, nonlinear simulations will be possible just as well.

The strength of the tsunami generated by a possible future Anak Krakatau explosion had to be chosen in advance; wave heights are determined by the strength. Since no scientific arguments are available to estimate this strength, a choice was made that leads to tsunami waves of significant wave heights of approximately $2 \mathrm{~m}$ in the Jakarta bay, resulting from an explosion with $1 / 4^{\text {th }}$ of the energy of the original Krakatau 1883 explosion.

Accepting the insecurity related to the unknown initiation scenario of the Anak Krakatau explosion, the presented results for the waves entering the $J B$ are quite robust, as indicated by results of various scenarios (not presented here) with different initiation scenarios. As a consequence, the simulated wave heights in the $J B$ without the presence of the wall are reliable because of the used small grid size and sufficiently accurate bathymetry.

Effects of waves from local winds, tides and storm surge have not been taken into account, and can be added in a linear approximation to the elevation from the tsunami; an integrated calculation of these effects is particularly useful for the optimal design with its much lower effect from the tsunami.

The simulated run-up heights on the different vertical wall shapes considered above give a good indication of the realistic heights to be expected. Further research is needed for more realistic designs of walls with slopes which will influence the run-up heights. Also friction that may reduce wave heights needs to be included.

For convex walls, the most importance aspect to be studies is the tangential flows along the wall. The interplay of a sloping wall, diffraction to the wall and refraction from the slope causes phenomenon that seem not to have had 
much attention in the literature yet. Another aspect is the assumption of linearity used in this report which could be relaxed by performing nonlinear simulations. Nonlinearity will influence the tsunami waves outside the wall, with some waves substantially higher. But it is not known what the nonlinear effect will be of waves on a sloping wall with oblique influx; it is known is that a Mach stem may develop on straight walls, with increased height at the wall $[6,7]$.

The optimization formulation considered here is rather rudimentary, taking only the concavity, the required area of the retention lake and the length of the wall into account. Other or additional constraints could be considered. For instance, instead of requiring a smallest length of the wall, a constraint of minimal cost could be considered when costs depend on the local depth at which the wall is build. More flexibility is obtained when relaxing the wavemotivated strict concavity constraint: a wall consisting of piecewise concave parts connected by straight walls could also have low waves; even the Garuda shape could still be included when placed further southwards parallel to the incoming waves along the optimal arc presented here.

\section{REFERENCES}

1. Master Plan National Capital Integrated Coastal Development, Final Version Dec. 2014; Boundary condition, INA556-3, C1.4. (INA556-3/agui/072), November 2013; Hydraulic assumptions: FHM and JCDS basics and specifications, INA556-3, C1.3a (INA556-3/agui/105), September 2014

2. Verbeek R. D. M., Krakatau. Gov. Press, Batavia, Indonesia, 1885 pp. 495

3. D. Adytia, M. Woran, E. van Groesen, Effect of a possible Anak Krakatau explosion in the Jakarta Bay, Proc. Basic Science International Conference 2012, Malang Indonesia, K1-5, ISBN 978-979-25-6033-6

4. HAWASSSI Variational Boussinesq Model (VBM), see www.hawassi.labmath-indonesia.org

5. Maeno F, F. Imamura (2011), Indonesian Journal of Geophysical Research, Vol. 116.

6. W. Li, H. Yeh, and Y. Kodama, J. Fluid Mech., vol. 672, pages 326-357, 2011

7. Lia Yuliawati, Nugrahinggil Subasita, Didit Adytia, Wono Setya Budhi, Simulation of Obliquely Interacting Solitary Waves with A Hard Wall by using HAWASSI-VBM and SWASH Model, Proceedings SEAMS 2015 